\title{
An analysis of curricular innovation in higher education: challenges and a possible solution
}

\author{
Iulia Gonta • Cristina Tripon •
}

\begin{abstract}
Curricular innovation in university education allows teachers to make use of a wide range of changes. What do teachers mean by "curricular innovation", how do they apply it and what are the factors that mobilize or block them in this process? These issues were analyzed based on the answers given by university teachers. Hence, we found that, although, at a theoretical level, teachers clearly formulate the needs of curricular development, at a practical/applied level, the action of curricular innovation is associated with uncertain objectives. A balance regarding variety/freedom of change in education would stimulate a more efficient innovation process (because excessive variety causes uncertainty and hinders action). Following the analysis of the teachers' answers, we found that they would be helped by the promotion of (only) successful innovative models, in which the possible application variants (and the results obtained depending on the local specifics, domain specifics, etc.) are specified. We believe that in this way, teachers will take be more active with respect to curricular innovation.
\end{abstract}

Keywords: curriculum, innovation, higher education, local specifics, teaching practices.

\section{Introduction}

Lately, the importance of modernizing education for the development of society is being mentioned more and more often, the process of innovation in the field of education becoming natural and necessary.

Recent social challenges have confirmed the urgent need to adapt the education system. The modernization of education is necessary both to keep pace with the development of scientific branches, the necessities of the labor market, and modern technologies.

To modernize education means to approach it innovatively and to generate solutions in line with society's present and future needs.

\section{Innovation in the context of Education}

The term "innovation" comes from Latin and means "renewal, novelty or change".

\footnotetext{
- Lecturer PhD, Polytechnic University of Bucharest, Romania, iuliagonta@gmail.com.

- Lecturer PhD, Polytechnic University of Bucharest, Romania, cristina.tripon@upb.ro. Both authors have an equal contribution to the publication
} 
Hassenforder (1974) defines the innovation of education as an attempt of any kind to consciously and deliberately aims to introduce a change in the education system in order to improve it.

Leithwood (1981) introduces the term curriculum innovation as the teachers' ability to use a new program, according to the changes required at different stages of development.

It turns out that, in the educational context, innovation involves the introduction of new and useful elements in the pedagogical activity, changes to the content and technology of teaching/learning/assessing, designed to increase the effectiveness of education.

Usually, curricular innovation means redesigning the curriculum in order to adapt it to current requirements. These changes may have different perspectives.

In higher education, curricular innovation aims to modify one or more curricular components, through changes regarding the content of education, teaching methods, teacher-student interaction, the organization of activities.

Curricular innovation involves reconceptualizing, modernizing, and optimizing the university curriculum. This is referring to the organizational, methodological, and content side of the educational process.

\section{Curriculum Innovation and Practices}

In this article, curricular innovation is approached in the sense of reconceptualizing, modernizing, and optimizing the university curriculum. This is referring to the organizational, methodological, and content side of the educational process.

The analysis of the literature on this subject shows that curricular innovation has been and is being studied in terms of changes in methods, forms, techniques, means, contents, objectives, etc.

Studying curricular innovation by defining and creating the curriculum serves to develop and implement educational policies. Studies that approach curricular innovation from this perspective aim to develop effective, sustainable, and developmental strategies such as that of Bovill and Woolmer (2019) on how conceptualizations of the curriculum in higher education influence student-staff co-creation or the studies of Franco, Saito, Vaughter and al. (2019), which argue about the influence of higher education in sustainable development: introducing global goals in policy, curriculum, and practice. Other authors, like Fishman and Krajcik (2003), talk about the process of creating sustainable science curriculum innovations. Voogt, Pieters, and Handelzalts (2016) analyze teacher collaboration in curriculum design teams: effects, mechanisms, and conditions. UK researchers Kirk, Newstead, Gann et al. (2018) have studied the benefits offered by the internationalization of the curriculum, as well as its related practices. This research indicates that the success of curricular policies depends to a large extent on the understanding of regional specificities, local problems, and needs. 
Davis and Krajcik (2005) have researched the great influence that designing educational curriculum materials has on promoting teacher learning while Cheng-Man Lau (2001) studies the curriculum development process by using three models: the modern model, the postmodern model, and the model suggested by the actor-network theory. Wall and Ryan (2010) described the design process of curriculum innovation in terms of learning styles, policies and procedures, curriculum tools, collaboration resources, social networking tools.

According to Ponnusamy (2019), the role of knowledge in curriculum innovation creates unique learning trajectories, in which teacher capacities and the contexts for curriculum innovation plays an important role.

Another type of approach to the research curriculum is related to the study and experimentation of new methods and technologies in education. Chee-Kit, Daner et al. (2018) describe the impact of a professional development model for a mobilized science curriculum from the teachers' perspective. Xiaolan, Yiwei, and Ying (2018) were concerned with the quality of the Chinese curriculum and studied how to streamline learning by using the MOOC teaching method. Also to this end, Cui (2018) designed and implemented an online platform to improve the quality of training, part of a successful curricular innovation.

Other researchers like Drake, Land and Tyminski (2014) suggest that using educational curriculum materials will support the development of prospective teachers' knowledge. About the process of curriculum design, Huizinga (2014) argues the importance of collaborative teams in developing curriculum design expertise through teacher design teams. This type of research offers teachers opportunities for continuous development, improvement, and advancement from a didactic point of view.

In 2018, Chediak, Bizelli, and Ryymin published the article "Brazil-Finland Dossier: Trends, Perspectives and Challenges of Education for The 21st Century", in which they justify capitalizing on the experiences of teachers in Brazil and Finland. It is this collaborative approach that has generated for the two countries the development strategy of their education for the 21st century.

In this context, we can state the importance of our research, which collected, systematized, and analyzed the experiences of university teachers and generated a prospective strategy for curricular innovation.

\section{Method}

\section{Research Objectives}

The objectives of our research followed two main directions of analysis, one in terms of current practice and the other in terms of proposals to improve the process of curricular innovation at the level of higher education. Hence, we defined the following directions:

1. Identifying the current situation, from the teachers' perspective regarding curricular innovation, in the context of challenges within higher education. 
2. Development of directions of curricular improvement following the specifics, objectives, and problems that exist in higher education.

\section{Participants}

The study was conducted between September 2019 and June 2020, with university teachers, participants in the project "Innovative Teachers - Student Entrepreneurs PISA!", co-financed by the European Social Fund through the Operational Programme Human Capital 2014-2020.

In the first stage, the research group included a number of 102 teachers, all students in teaching training programs. Their selection was not made according to any criteria, but rather they became a research group because they expressed their anonymous interest. Subsequently, some respondents refused to answer all questions. In the final form, the selection of participants was made from the perspective of active involvement in the research (the refusal to answer a question entailed the elimination of the respondent). Thus, the new target group was outlined: 75 university teachers, working in the following fields: mechanics and technology, economics, law, electronics, communications, computers, physical education, computer science, educational sciences, social sciences, psychology, theology, languages, history, arts (Fig. 1). The respondents were between 29 and 52 years old, had a seniority of between 1 and 25 years (Fig. 2).

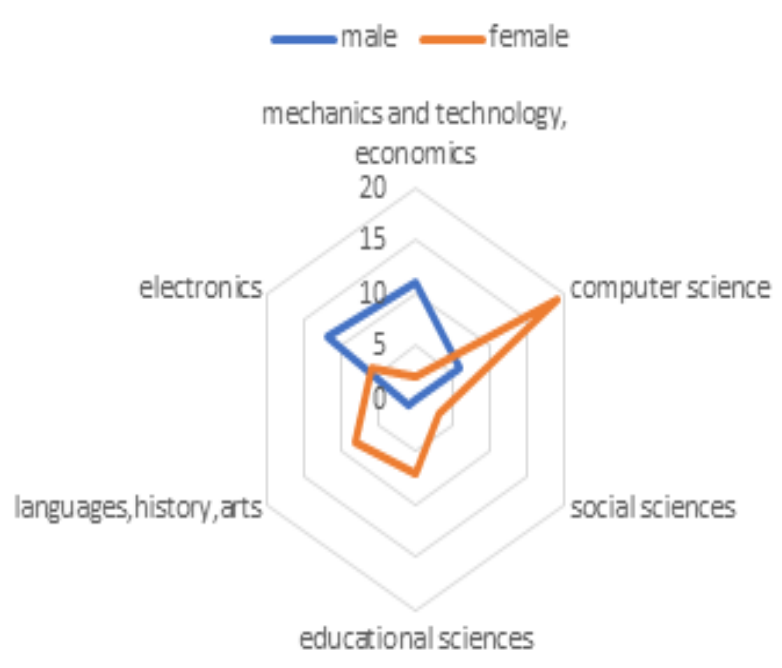

Figure 1: Respondents' gender and teaching distribution

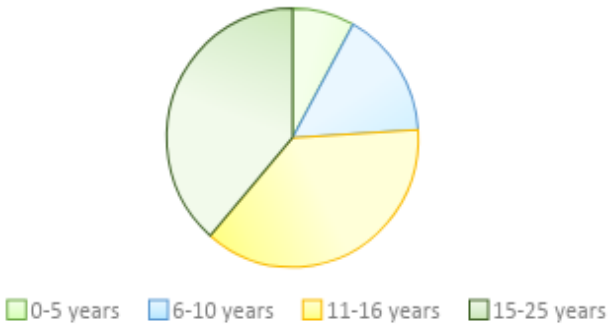

Figure 2. Respondents' seniority of education (in years) 


\section{Instruments and Procedure}

The first stage of the research involved the use of questionnaires to collect the teacher's personal data.

Subsequently, in order to identify the current situation regarding curricular innovation, from the teachers' perspective, in the context of challenges within higher education, the university teachers completed a set of online questionnaires (through Moodle). The following questionnaires were used:

1. Questionnaire on the "Factors that Influence the Process of Curricular Innovation in Higher Education" (multiple choice). The questionnaire included 4 questions, namely: What are the resources needed to initiate and implement the innovation process in higher education? What factors motivate the innovation process? What barriers are there to becoming a teacher-innovator? What helps in solving the problems (barriers) that appear during the innovation process?

2. Questionnaire on how teachers understand the curriculum innovation process: "Is innovation an adaptation or an essential change?" (binary choice)

The procedure of data collection, analysis, and synthesis was performed by independent researchers, precisely to avoid the hindering of the quality of the data obtained. Before the actual application, the questionnaire was pre-tested and analyzed for the removal of non-compliant items, the final internal consistency coefficient Alpha Cronbach (Cohen, 1988) being 0.76, which means that the data obtained have high validity (Table 1).

Table 1. Reliability of research instrument (questionnaire)

\begin{tabular}{lccc}
\hline Variable & $\begin{array}{c}\text { Number } \\
\text { of items }\end{array}$ & $\begin{array}{c}\text { Reliability } \\
\text { (Cronbach`s } \\
\text { alpha) }\end{array}$ & Comment \\
\hline $\begin{array}{l}\text { Resources needed to initiate and } \\
\text { implement the innovation process in } \\
\text { higher education } \\
\quad \text { Factors that motivate the }\end{array}$ & 12 & 0.78 & Accepted \\
$\begin{array}{l}\text { innovation process } \\
\text { Factors that hinder the rise to }\end{array}$ & 9 & 0.71 & Accepted \\
become a teacher-innovator \\
$\quad$ Limits to problem-solving \\
(blockages) which appear during the
\end{tabular}

After the primary processing of the data obtained from the questionnaires (which have been completed online), the respondents' answers were discussed in focus groups. 
These were created in order to outline in the context of a group of teachers common opinions on the perspectives of curricular development and conceive new directions of curricular improvement following the specifics, objectives, and problems that exist in higher education. The teachers' answers (within the focus groups) implied the directions of action that they associate with the innovation of university curricula.

Then individual interviews with teachers were organized, which were necessary to understand the teachers' answers. Thus, we excluded the mutual influence of the participants from the focus groups and we deepened the qualitative research, to outline conclusions (quotes belonging to the interviewees are presented in the section "Results on How University Teachers Understand Innovation: Teachers' Directions of Action")

Conducting interviews was the stage that required a large number of researchers involved, given its complexity. The analysis of the data obtained from qualitative research was performed by independent researchers with experience in social sciences and humanities, other than those involved in data collection, this being necessary for a more transparent and objective selection of data of interest, without them being prone to reinterpret the meaning or reorganize the content.

In this way, we obtained qualitative data that captured perceptions and opinions, but also directions for the development and improvement of the university curriculum.

\section{Analysis of the Results}

Results regarding the attitude of university teachers towards the process of curricular innovation

During the research, the teachers completed a questionnaire with questions on what are the resources needed to initiate and implement the innovation process in higher education, what factors favor or block the innovation process. The answers to these questions showed the following:

- In order to initiate and implement the process of curricular innovation, it is necessary for teachers, first of all, to have an openness towards change/innovation.

- The most motivating factor in the implementation of curricular innovation is considered by teachers to be the awareness of the importance of modernizing education (more important than the freedom to express oneself personally or to carry out activities based on common interests).

- To become a teacher-innovator you have to give up passivity and the feeling of self-sufficiency.

- Innovation bottlenecks can be solved, firstly, by clearly formulating objectives and, secondly, by motivating working conditions and a team of people with a similar way of thinking.

Details regarding the results of this questionnaire are included in the table below (Table 2 and Table 3). 
Table 2. Responses to the questionnaire on "Factors that Influence the Process of Curricular Innovation in Higher Education" (mean assigned importance in \%)

\begin{tabular}{lc}
\hline \multicolumn{1}{c}{ Question } & Mean (\%) \\
\hline What are the resources needed to initiate and & \\
implement the innovation process in higher & \\
education? & 42,76 \\
- Openness to innovative experiences & 20,11 \\
- Following examples of innovation & 37,13 \\
- Research and experimentation skills & \\
\hline What factors motivate the innovation process? & 28,73 \\
- Freedom of expression & 39,32 \\
- Awareness of the role of innovation in the development of the so' \\
- Common activities and interests & 32,86 \\
\hline What hinders the rise to become a teacher- & \\
innovator? & 23,49 \\
- The feeling of self-sufficiency & 19,11 \\
- Previous failed attempts & 21,75 \\
- Superficially substantiated conclusions & 25,68 \\
- Passivity & 10,87 \\
- Wishes impossible to fulfill & \\
\hline What favors solving the problems (blockages) & 17,85 \\
that appear during the innovation process? & 28,63 \\
- Psychological support & \\
- A team of people with a similar way of & 30,99 \\
- thinking & 23,52 \\
- Motivating working conditions &
\end{tabular}

From table 2 we notice the following:

- for the question "What are the resources needed to initiate and implement the innovation process in higher education?" university teachers preferred the answer "Openness to innovative experiences" (43\%);

- to the question "What factors motivate the innovation process?" in the first place is the answer "Awareness of the role of innovation in the development of society" (39\%);

- the most frequently answered answer to the question "What hinders the rise to become a teacher-innovator?" is "Passivity" (26\%);

- to the question "What favors solving the problems (blockages) that appear during the innovation process?" university teachers preferred the option "Clarity in formulating objectives" (30\%). 
Table 3. Responses to the questionnaire on "Factors that Influence the Process of Curricular Innovation in Higher Education" (when ranked by assigned importance)

\begin{tabular}{|c|c|}
\hline Question & Mean Rank \\
\hline $\begin{array}{l}\text { What are the resources needed to initiate and implement the } \\
\text { innovation process in higher education? } \\
\text { - Openness to innovative experiences } \\
\text { - Following examples of innovation } \\
\text { - Research and experimentation skills }\end{array}$ & $\begin{array}{l}1.619718 \\
2.845070 \\
2.028169 \\
\end{array}$ \\
\hline $\begin{array}{l}\text { What factors motivate the innovation process? } \\
\text { - Freedom of expression } \\
\text { - Awareness of the role of innovation in the development of th } \\
\text { society }\end{array}$ & $\begin{array}{l}2.394366 \\
1.985915 \\
2.014085\end{array}$ \\
\hline $\begin{array}{l}\text { What hinders the rise to become a teacher-innovator? } \\
\text { - The feeling of self-sufficiency } \\
\text { - Previous failed attempts } \\
\text { - Superficially substantiated conclusions } \\
\text { - Passivity } \\
\text { - Wishes impossible to fulfill }\end{array}$ & $\begin{array}{l}3.253521 \\
3.563380 \\
3.070423 \\
2.873239 \\
4.647887\end{array}$ \\
\hline $\begin{array}{l}\text { What favours solving the problems (blockages) that } \\
\text { appear during the innovation process? } \\
\text { - Psychological support } \\
\text { - A team of people with a similar way of thinking } \\
\text { - Clarity in formulating objectives } \\
\text { - Motivating working conditions }\end{array}$ & $\begin{array}{l}3.619718 \\
2.774648 \\
2.492958 \\
2.816901 \\
\end{array}$ \\
\hline
\end{tabular}

The processing of the raw data involved the following steps: first, each answer was given a rank between one and the number of questions in the respective group. For example, if Q1 were assigned a weight of 10\%, Q2 - 70\%, and Q3 - 20\%, then Q1 would be ranked in the 3rd place, Q2 - 1st place, and Q3 - 2nd place. The next step consisted of averaging the rank for each question over every participant. Thus, a smaller rank represents a higher importance.

N.B.: In case two or more questions were assigned the same weight, the following formula was used to calculate their rank: number of questions in the group - number of questions whose weight is less than the analysed question's weight.

The results of this questionnaire show that university teachers consider it important not only to be aware of the role of curricular innovation for society and the desire to innovate, but also to clearly formulate objectives (which allow for getting out of passivity). This fact reminds us of a more directive teaching approach by offering clear and concrete solutions, coming from specialists and authorities. 


\section{Results regarding teachers' responses to what innovation is: an adaptation or a total change?}

University teachers were asked to answer the question "Do you think that the Romanian university curriculum needs only an adjustment/adaptation to socio-cultural development or is an essential and radical change necessary?"

Following the collection of answers, it was found that the vast majority of teachers feel the need for a change in education (88\% chose adaptation and $12 \%$ - radical change in the university curriculum).

Next, we will show the significance that university teachers assign to the change of the curriculum, grouping their answers in the following innovative directions: adapting the university practices to the needs of society, continuous curriculum improvement, modern technologies for adapting students to the labor market, adaptive teaching methods, adapting the curricular contents according to the skills required in the $21^{\text {st }}$ century, adapting successful practices from other countries, teaching both students and teachers reflective practice, teacher training for their new roles.

\section{Results on How University Teachers Understand Innovation: teachers' Directions of Action}

1. Adapting the University Practices to the Needs of Society. Participants in the interview supported curricular adaptation to the challenges of contemporary society, which is much different from the one in which they specialized and trained as teachers. From this perspective, they support the training of students, both in the direction of professional skills and in the direction of personal development. Thus, there exists a direction that would imply the modification of the curricular contents and the professional competences derived from the university programs, following the competencies required of the students on the labor market: entrepreneurial, transversal, and other competencies.

"The Romanian university curriculum needs to be adapted to the reality in which we live. Today's society is completely different from the society in which we trained, personally, and professionally. Professional development must be accompanied by personal development and emotional development. The university curriculum must integrate content and methods that develop transversal skills and knowledge, entrepreneurial skills, and attitudes to help the students to easily integrate into the labor market."

Often, teachers agree that the university training of students is not in line with the requirements of the employers, this requiring clear regulations, especially due to the dynamics of the skills needed for the active integration of the students into the labor market:

"University programs/curricula should prepare future specialists for the needs of the labor market, but often the needs and requirements of the job market are not found in the educational offer of the faculties/universities. One can identify the lack of 
correlation of university training programs/curricula with the labor market through the employment rate of graduates if university programs were correlated with the needs and requirements of the labor market, then the employability of the graduates would no longer be a problem"

Also, the university teachers suggest alternatives to solve this problem.

"A first step is to perform a situational analysis, through which it is desired to identify the degree of correlation and adaptation between the curricula, the degree of applicability of information accumulated during training, the quality of teaching methods and techniques, objectivity of evaluation, student involvement in activities (academic and scientific), the relevance of the internships, the opportunities offered by the faculty/university, the contacts with the key people in the field, the attractiveness of the study programs, the demand for specialists by the labor market, the employment rate of the graduates."

2. Adapting the Curricular Contents According to the Skills Required in the 21st Century. All teachers agree that the change that can be discussed in university education is also related to updating the contents of university programs and changing the paradigm from knowledge to application.

"The curriculum should be reoriented from knowledge ("knowing") to practical application and problem-solving ("knowing how" / "doing" - including the "wanting to do" attitude component). As a result, the evaluation should be reoriented: from "I know", simply, to "I know" + "I can" + "I want" -

Also, the respondents agree with the introduction of new development skills among graduates, precisely due to globalization and the need for continuous adaptation for their integration as active citizens into the labor market.

"The world is changing around us from day to day, and new technologies and evolution of the global economy force us to modernize the education system as well. Children need to learn to think critically, to be creative, to work in a team, to be able to adapt as they go, because today's professions could be history tomorrow. Moreover, in school, we should learn and practice real-life."

3. Continuous Curriculum Improvement. According to the data obtained, the respondents believe that the development of the university curriculum should be carried out continuously, a necessary measure for the quality of the services offered by the university to its students. It should also be easy for universities to adapt, precisely because of their total autonomy from the education system (which is known for excessive bureaucratization, especially when it comes to curriculum development).

"The new economic and social context implies changes and performance in all fields of human activity. Ensuring the quality of education, in this sense, has consequences on the quality of human resources, social cohesion, economic competitiveness, and, ultimately, on the quality of life. In this regard, the quality of the curriculum and the management of the university curriculum are some of the most important requirements for higher education. Thus, any higher education institution, 
in the context of university autonomy, is responsible - autonomously - for the development of institutional curricular policies. From my point of view, the university curriculum in Romania requires adaptation to the socio-cultural development by introducing new structural elements, by streamlining teaching technologies, by modifying the skills system, by introducing new content units, etc. I am not an adept of radical changes, but of keeping the good elements and adapting them to the new realities."

4. Adaptive Teaching Methods. From the results obtained, the continuous development of teaching and learning methods seems intensely discussed and seen as in an acute need for change. All the respondents touched on the subject of adopting teaching methods, either directly or through the need for continuous development of the teaching career, through professional development training in this direction. An important related point is the training of teachers in the context of each discipline/specialty and not in general (as is currently the case). The teachers complained that both the initial and the continuous training of the teachers have a general aspect, without a concrete specificity, and educational practice is deficient. It is also added that the development of these methods should be in line with research in the field of learning and relevant teaching practices and also considering the students' perspective (not just the teachers').

"Regarding teaching/learning methods, I believe that combining classical and modern methods, together with practical examples, can ensure a thorough understanding and awareness of fundamental principles and phenomena on which many of the applications of a field of study will be based."

"I think that there are many aspects to be improved in the Romanian curriculum and I also believe that any sustainable process/change must be done gradually, through modifications and adaptations/improvements, the addition of new teaching-learning methods and practices, but also keeping the old ones that have proven to be effective and have worked. By adding new, modern, attractive methods, along with the established and efficient ones, the degree of innovation and motivation of both parties involved in the educational process, teachers and students, will be increased."

5. Modern Technologies for Adapting Students to the Labor Market. Regarding the adaptation of the universities to the labor market, teachers think that it is a must to take into account technological and scientific progress, to keep pace with the development of scientific fields, to master the high level of complexity of modern technologies, and to generate a society in line with the specific needs of the time. Adaptation must also aim to develop the professional skills, required by employers or offered by the resources of each individual person. Socio-technological evolution imposes a new, much faster pace of skill acquisition and increased adaptability to the (ever-changing) demands of the labor market.

"Staying with the old methods and technologies of teaching, studying, and analyzing the classic situations of a field, is, in my opinion, a redundant issue, which can not keep up with the progress of these years in which we operate." 
6. Adapting Successful Practices from Other Countries. From the data obtained from interviews and focus groups, it appears that teachers believe that the development of university practices should be done following the socio-cultural environment of the country. They think that it is very important to analyze the successful practices of other countries, but they do not see their integration in the Romanian curricular innovation without an adaptation to the socio-cultural level.

"If there are good things to borrow from others, let us borrow, of course, if this suits our teaching style and the disciplines we teach. Using a metaphor - when a house is relatively well built, the rationale is not to "give it away", but to consolidate and renovate it - of course, depending on one's "fashion", needs, possibilities, and taste. Adjustments to socio-economic and cultural-historical realities are, of course, necessary, because we have to relate to real life and because we will give the labor market graduates who have to deal with this reality."

7. Teaching Both Students and Teachers Reflective Practice. Most university teachers claim that there is no need for an "essential and radical change" of the Romanian university curriculum, but "an adjustment/adaptation to socio-cultural development" is necessary to critical reflection on ways to improve learning experiences for students (for example, the fact that the interactive method not only has the effect of making a learning activity more attractive but can motivate students and help to optimize learning); reporting on the learning contents from the perspective of competences; stimulating the participation in group activities, in educational projects to form participatory behaviors; supporting learning activities during classes through other activities carried out in nonformal educational contexts.

It is necessary to change the mentality of learning, just so that students no longer hate school, but collaborate within it.

"What needs to change fundamentally is how our students learn. Learning is what happens on the way to a goal. We don't have to ask students to learn. We need to ask them to solve specific case studies, which can be achieved using learning as a means. This is why children hate school. The school focuses on learning itself. If chemistry were focused on building fireworks ... all children would know chemistry."

8. Teacher Training and the New roles of Teachers. The interviewed teachers felt overwhelmed by the continuous changes and the adaptations on which these changes in education should be based. In a country that invests poorly in education (only $3 \%$ of GDP) and especially the fact that initial and continuing training is the individual responsibility of teachers (including its costs), respondents believe that the number of roles teachers have is increasing every year.

"Teachers fail to fully meet current requirements and are constantly looking for solutions in this regard. Unfortunately, teachers in the education system do not fully meet the current requirements. Teacher training institutions are constantly looking for solutions in this regard. Because universities must prepare students according to the 
requirements of current and future society, teacher training must reflect the high demands of all stakeholders in education."

Therefore, the respondents claim that, from the moment of their initial teacher training until the current moment, many changes have taken place. Also, because of the new needs of education as well, teachers think that "people and organizations are constantly becoming consumers and creators of media, and the level of interconnection generates behavioral patterns difficult to imagine in the recent past, and the training of the teachers becomes difficult".

\section{Conclusions}

The analysis of the data obtained from the research allowed us to identify the current situation and the teachers' perspective regarding curricular innovation, to understand the specifics and problems that exist in higher education.

Following the research, we found that university teachers have different definitions for curricular innovation. As a consequence, the plethora of innovation possibilities confuses university teachers and as a result, they prefer the position of the passive observer. In other words, the subjective and extremely different understanding of what innovation in education means is a factor that slows down change.

The university teachers suggested the following directions for curricular innovation: adapting the university practices to the needs of society and the curricular contents according to the skills required in the 21st century, improving continuous curriculum, introducing adaptive teaching methods and modern technologies for adapting students to the labor market, adapting successful practices from other countries, teaching both students and teachers reflective practice, and promoting teacher training.

The fact that there are many directions of innovation (the variety of directions of development was analyzed in the section "Curriculum Innovation and Practices"), leads to the idea that innovation must be approached holistically, permanently, from all perspectives.

Another idea that emerged during the research, derived from teachers' responses, states that curricular innovation must be accompanied by clear objectives. Moreover, we believe that teachers need not only clear goals, but also concrete examples of success and quality in education. We believe that in this way, teachers will take be more active with respect to curricular innovation.

\section{References}

Bovill, C., Woolmer, Ch. (2019). How conceptualisations of curriculum in higher education influence student-staff co-creation in and of the curriculum. The International Journal of Higher Education Research, 78, 407-422.

Chediak, S., Bizelli, J. L., Ryymin, E. (2018). Brazil-Finland Dossier: Trends, Perspectives and Challenges of the Education for The 21st Century, Revista Ibero-Americana de Estudos em Educação, 13 (1), 278-290.

Cohen, J. (1988). Statistical power analysis for the behavioral sciences (2nd ed.). Hillsdale, NJ: Lawrence Earlbaum Associates. 
Cui, L. (2018). Design and Implementation of I \& P Resource Sharing Platform Based on Excellent Curriculum Repository. Educational Sciences-Theory \& Practice, 18, 3784-3795.

Davis, E. A., Krajcik, J. (2005). Designing educative curriculum materials to promote teacher learning. Educational Researcher, 34(3), 3-14.

Hassenforder, J. (1974). L'innovation dans l'enseignement. Revue française de pédagogie, 26, 42-44.

Lau, D. C.-M. (2001). Analysing the curriculum development process: three models. Pedagogy, Culture \& Society, 9:1, 29-44.

Drake, C., Land, T. J., \& Tyminski, A. M. (2014). Using educative curriculum materials to support the development of prospective teachers' knowledge. Educational Researcher, 43, 154-162.

Fishman, B., Krajcik, J. (2003). What does it mean to create sustainable science curriculum innovations? A commentary. Science Education, 87 (4), 564-573.

Franco, I., Saito, O., Vaughter, P., et al. (2019). Higher education for sustainable development: actioning the global goals in policy, curriculum and practice. Sustainability Science, 14, 1621-1642.

Huizinga, T. (2014). Developing curriculum design expertise through teacher design teams, PhD Thesis, Enschede, Universiteit Twente. Retrieved from http://doc.utwente.nl/93179/1/thesis_T_Huizinga.pdf .

Kirk, S., Newstead, C., Gann, R. et al. (2018). Empowerment and ownership in effective internationalisation of the higher education curriculum. Higher Education, 76, 989- 1005.

Leithwood, K.A. (1981). The Dimensions of Curriculum Innovation. Journal of Curriculum Studies, 13 (1), 25-36.

Ponnusamy, L. D. (2019). Teacher Learning in Curriculum Innovation, the Unique Case for Embedded Learning. In Peters M., Heraud R. (Eds.), Encyclopedia of Educational Innovation. Singapore: Springer.

Voogt, J., Pieters, J., Handelzalts, A. (2016). Teacher collaboration in curriculum design teams: effects, mechanisms, and conditions. Educational Research and Evaluation, 22 (3-4), 121-140.

Wall, J., Ryan, S. (2010). Resourcing for curriculum innovation, Australia: Mc Phersons Printing Group.

Xiaolan, G., Yiwei, Y., Ying, W. (2018). MOOC Education Mode of PE Public Curriculum in Colleges and Universities Based on Data Mining. Educational Sciences-Theory \& Practice, 18 (6), 3160-3168. 